\title{
GLOBAL VIEW
}

\section{Chlamydia trachomatis infection among sexually active young women in Italy}

\author{
M A Latino, L Bello, A Lanza, E Leotta, P Tersiev, G De Intinis, E Spagnolo, C Smirne, \\ R Grio
}

Objectives: Chlamydia trachomatis infection is the most common sexually transmitted disease among sexually active adolescents and young adults in Europe. The goal of this study was to determine the prevalence of $C$ trachomatis among young women in Turin, Italy, and the correlation between some risk factors and $C$ trachomatis infection. Methods: In our study 3314 sexually active women between the ages of 14 and 25 were screened for $C$ trachomatis by ligase chain reaction (LCR) using cervical swabs during the period 1997-2000 at the Turin School of Medicine. All the patients answered a specific questionnaire.

Results: In our analysis the prevalence of $C$ trachomatis infection was found to be $3.5 \%$, and the average age among the infected patients was 22.12 years. Statistical analysis was performed using the $\chi^{2}$ test. A $p$ value $<0.05$ was considered significant. A correlation was found between a positive result and: membership of east European and central northern Africa populations $(p<0.001)$, low levels of education $(p<0.001)$, age at the first intercourse $(p=0.006)$, the presence of symptoms in the women $(p<0.001)$, and the number of sexual partners in the preceding 6 months $(p<0.001)$. No statistically significant difference was found among the contraceptive methods used whether hormonal or a barrier type and with the subjective symptoms of the partner.

Conclusion: Frequent microbiological examinations are desirable for patients whose anamnesis shows an increased risk of contracting sexually transmitted infections in order to avoid long term complications from misdiagnosed or asymptomatic pathologies; this often happens with $C$ trachomatis infection.

\footnotetext{
C
} hlamydia trachomatis, an obligatory intracellular bacteria, is the most common sexually transmitted disease in sexually active young adults in Europe. ${ }^{1}$ The symptoms can be mild, non-specific, or even not present. In males the most common symptom is urethritis. Infected asymptomatic men can unknowingly transmit the infection. Complications are rare, but the ones deriving from an undiagnosed infection of $C$ trachomatis include pelvic inflammatory disease (PID), infection of Bartholin's glands, extrauterine pregnancy, and infertility. ${ }^{2}$

$C$ trachomatis infections are most often found in adolescents ${ }^{3}$ and PID is found more often in adolescent females than in adult women. ${ }^{4}$ The anatomy of the female reproductive system, especially in younger women, contributes to the spread of the disease. Adolescent women commonly have a normal cervical anatomical finding known as the ectropion, which is exposed to the vaginal environment and thus leads to a high risk of infection. While the mucus in older women is denser due to hormonal modifications result- ing from the maturation of the hypothalamic-pituitary axis, it is more fluid in younger women, especially among those with a high prevalence of anovulatory cycles, which are deficient in progesterone. This permits a more rapid spread of the pathogens towards the upper genital tracts with an increased risk of PID.

The prevalence of $C$ trachomatis infection in the general population is uncertain, due to the asymptomatic nature of the disease and the necessity of a bacteriological examination for diagnosis. The introduction of new tests based upon the amplification of DNA, such as polymerase chain reaction (PCR), makes it possible to use urine samples for the diagnosis. Because of heightened sensitivity and specificity these tests permit screening on a vast scale for $C$ trachomatis. ${ }^{56}$ The goal of this study was to determine the prevalence of $C$ trachomatis among young women in Turin, Italy, and the correlation between some risk factors and $C$ trachomatis infection.

\section{MATERIALS AND METHODS}

From January 1997 to the end of December 2000, 3314 unselected sexually active women, aged 14-25 years, had a vaginal bacteriological test at the department for genitourinary infections and sexual health of St Anna Hospital in Turin. Cervical specimens were tested for $C$ trachomatis using the technology of amplification of nucleic acids by means of ligase chain reaction (LCR) using the Abbot LCx system (LCx, Abbot Laboratories, Chicago, IL, USA) according to the manufacturer's instructions. This dosage permits a direct qualitative finding of plasmidic DNA of $C$ trachomatis in cervical swabs. The product generated during the LCR reaction is evidenced with the Abbot LCx analyser.

Statistical analysis was performed using the $\chi^{2}$ test. A p value of less than 0.05 was considered significant.

All the patients answered a specific questionnaire which included information concerning citizenship, level of education, age at the time of the first sexual intercourse, the number of sexual partners, methods of contraception used, gynaecological problems, complaints, subjective symptoms, and lifestyle habits (drug use, etc) (table 1). Given the multiplicity of the parameters which were found and the wide range of responses, in order to calculate correlations among the several variables it appeared useful to unite various subgroups, for each single factor comparing two groups of patients.

\section{RESULTS}

In our analysis the prevalence of $C$ trachomatis infection was found to be $3.5 \%$, with an average age of 22.12 years among the infected patients.

The risk factors most frequently associated with $C$ trachomatis infection are listed in table 2: ethnicity, a low level of education, age at first intercourse, use of injecting drugs, gynaecological complaints, the number of sexual partners, and the partners' complaints. 


\begin{tabular}{|c|c|c|}
\hline & \multicolumn{2}{|c|}{ Chlamydia trachomatis } \\
\hline & $\mathrm{CT}+$ & $\mathrm{CT}-$ \\
\hline Number & $112(3.5 \%)$ & $3202(96.5 \%)$ \\
\hline Median age & 22.12 & 22.49 \\
\hline \multicolumn{3}{|l|}{ Ethnicity } \\
\hline Non-communitarian & $26(9.56 \%)$ & $272(90.44 \%)$ \\
\hline Communitarian & $85(2.9 \%)$ & $2924(97.1 \%)$ \\
\hline Unknown & $1(16.67 \%)$ & $6(83.33 \%)$ \\
\hline \multicolumn{3}{|l|}{ Education } \\
\hline None & $2(11.76 \%)$ & $17(88.24 \%)$ \\
\hline Primary school & $5(8.47 \%)$ & $59(91.53 \%)$ \\
\hline Secondary school & $59(4.83 \%)$ & $1222(95.17 \%)$ \\
\hline High school & $45(2.48 \%)$ & $1814(97.52 \%)$ \\
\hline University & $0(0 \%)$ & $49(100 \%)$ \\
\hline Unknown & $1(2.44 \%)$ & $41(97.56 \%)$ \\
\hline \multicolumn{3}{|c|}{ Age of first sexual intercourse } \\
\hline$\leqslant 15$ & $24(5.53 \%)$ & $434(94.47 \%)$ \\
\hline $16-17$ & $34(3.48 \%)$ & $977(96.52 \%)$ \\
\hline $18-25$ & $41(2.55 \%)$ & $1609(97.45 \%)$ \\
\hline \multicolumn{3}{|l|}{ Contraception } \\
\hline None & $48(3.43 \%)$ & $1401(96.57 \%)$ \\
\hline E-P pill & $34(3.27 \%)$ & 1039 (96.73\%) \\
\hline \multicolumn{3}{|l|}{ Condoms } \\
\hline Always & $14(3.12 \%)$ & 449 (96.88\%) \\
\hline Sometimes & $8(5.52 \%)$ & $145(94.48 \%)$ \\
\hline Others & $4(3.96 \%)$ & $101(96.04 \%)$ \\
\hline IUD & $0(0 \%)$ & $14(100 \%)$ \\
\hline Unknown & $4(7.55 \%)$ & $53(92.45)$ \\
\hline
\end{tabular}

A statistically significant correlation $(\mathrm{p}<0.001)$ was found between a positive result on the test and membership in noncommunitarian populations (non-communitarian being those patients of east European and central northern Africa origin). The level of education was found to be significant too, evidenced by a greater prevalence of positive results among patients with low levels of education compared with those having a secondary school and/or a university diploma. The age at the first intercourse and the number of partners in the preceding 6 months were also found to be significant. No statistically significant difference was found among the contraceptive methods used, whether hormonal or a barrier type, and there is no correlation with the subjective symptoms of the partner.

As regards the odds ratio (OR), one should note the importance of the level of education ( $\mathrm{OR}=2.07)$ and membership in non-communitarian populations $(\mathrm{OR}=3.29)$, whether sexual activity was begun before 15 years of age $(\mathrm{OR}=1.91)$, the presence of complaints in the women $(\mathrm{OR}=2.35)$, and number of sexual partners in the preceding 6 months $(\mathrm{OR}=3.06)$ as factors that significantly increase the risk of disease. The use of injecting drugs is also correlated with a risk of infection that is 2.74 times higher than the risk to non-drug users.

\section{CONCLUSIONS}

The side effects of this infection upon the health of individuals and upon the public health budget lead one to consider the control of the spread of $C$ trachomatis as a priority. Indeed, Burstein et $\mathrm{al}^{7}$ advise testing sexually active adolescents for $C$ trachomatis every 6 months. The population evaluated in their study was homogeneous (98\% African American), different from the Italian reality. In screenings performed in other countries (Sweden and USA) ${ }^{8}$ the prevalence of $C$ trachomatis infection varies from $3 \%$ to $6 \%$, placing our cohort examined in the lowest level $(3.5 \%)$. In the light of these results, it does not seem advisable to screen every 6 months all the sexually active adolescents in our community, but particular attention should be paid to the migration of new high prevalence non-communitarian subgroups into northern Italy. In accord with other Italian studies, ${ }^{9}$ frequent microbiological examinations are desirable for patients whose clinical history shows an augmented risk of contracting sexually transmitted infections in order to avoid long term complications from misdiagnosed or asymptomatic pathologies.

\begin{tabular}{|c|c|c|c|c|c|}
\hline & No & $\mathrm{CT}+$ & $\mathrm{p}$ Value & OR & \\
\hline Number & 3314 & $112(3.5 \%)$ & & & \\
\hline \multicolumn{6}{|l|}{ Ethnicity } \\
\hline Non-communitarian & 298 & $26(8.72 \%)$ & & & \\
\hline Communitarian & 3009 & $85(2.82 \%)$ & $<0.001$ & 3.29 & $2.03<O R<5.30$ \\
\hline Unknown & 7 & $1(14.28 \%)$ & & & \\
\hline \multicolumn{6}{|l|}{ Education } \\
\hline Compulsory school & 1345 & 64 & & & \\
\hline High school + university & 1908 & 45 & $<0.001$ & 2.07 & $1.38<O R<3.10$ \\
\hline \multicolumn{6}{|l|}{ Age of first sexual intercourse } \\
\hline$\leqslant 15$ & 458 & $24(5.88 \%)$ & & & \\
\hline $16-17$ & 1011 & $34(3.36 \%)$ & & & \\
\hline $18-25$ & 1650 & $41(2.55 \%)$ & 0.006 & 1.91 & $1.16<O R<3.12$ \\
\hline Non-responders & 99 & $8(8 \%)$ & & & \\
\hline Unknown & 96 & $5(5.21 \%)$ & & & \\
\hline \multicolumn{6}{|l|}{ Contraception } \\
\hline None & 1449 & $48(3.43 \%)$ & & & \\
\hline E-P pill, condom, sterilisation & 1865 & $64(3.55 \%)$ & NS & 0.96 & $0.65<O R<1.43$ \\
\hline \multicolumn{6}{|l|}{ Injecting drugs } \\
\hline Yes & 59 & $5(8.47 \%)$ & & & \\
\hline No & 3179 & $104(3.27 \%)$ & 0.028 & 2.74 & $0.94<O R<7.32$ \\
\hline Non-responders & 75 & $3(4 \%)$ & & & \\
\hline \multicolumn{6}{|l|}{ Symptoms } \\
\hline Yes & 1917 & $85(4.43 \%)$ & & & \\
\hline No & 1397 & $27(1.93 \%)$ & $<0.001$ & 2.35 & $1.49<O R<3.74$ \\
\hline \multicolumn{6}{|c|}{ No of sexual partners during past 6 months } \\
\hline$>1$ & 126 & $11(8.73 \%)$ & & & \\
\hline$\leqslant 1$ & 2935 & $89(3.03 \%)$ & $<0.001$ & 3.06 & $1.50<O R<6.08$ \\
\hline Non-responders & 253 & $12(4.74 \%)$ & & & \\
\hline \multicolumn{6}{|l|}{ Partner } \\
\hline Symptomatic & 165 & $8(4.85 \%)$ & & & \\
\hline Non-symptomatic & 3149 & $104(3.30 \%)$ & NS & 1.49 & $0.66<O R<3.23$ \\
\hline
\end{tabular}




\section{Authors' affiliations}

M A Latino, G De Intinis, E Spagnolo, AOU Virology and Microbiology, Department of Clinical Pathology, Azienda Ospedaliera Materno Infantile OIRM Sant'Anna, Via Ventimiglia, 3, Torino, Italy L Bello, A Lanza, E Leotta, P Tersiev, R Grio, Department of Obstetrics and Gynecology, University of Turin, Azienda Ospedaliera Materno Infantile OIRM Sant'Anna, Via Ventimiglia, 3, Torino, Italy

C Smirne, Department of Clinical Physiopathology, University of Turin, Azienda Ospedaliera Molinette, C so Bramante, 88, Torino, Italy

Correspondence to: Luca Bello; Ibello@inwind.it

Accepted for publication 29 May 2002

\section{REFERENCES}

1 CDC. Recommendations for the prevention and management of Chlamydia trachomatis Infections. MMWR 1993;42(RR-12)
2 Paavonen J, Eggert-Kruse W. Chlamydia trachomatis: impact on human reproduction. Hum Reprod Update 1999;5:433-47.

3 Holmes KK, Sparling PF, Mardh P-A, et al, eds. Sexually transmitted diseases. 3rd ed. New York: McGraw-Hill, 1999.

4 Westrom L, Svensson L, Wolner-Hanssen P, et al. Chlamydial and gonococcal infections in a defined population of women. Scand J Infect Dis 1982:32 (suppl): 157-62.

5 Lee HH, Chernesky MA, Schachter J, et al. Diagnosis of Chlamydia trachomatis genitourinary infection in women by ligase chain reaction assay of urine. Lancet 1995;345:213-16.

6 Schachter J, Moncada J, Whidden R, et al. Noninvasive tests for diagnosis of Chlamydia trachomatis infection: application of ligase chain reaction to first-catch urine speciments of women. J Infect Dis 1995; 172:1411-14.

7 Burstein GR, Gaydos CA, Diener-West M, et al. Incident Chlamydia trachomatis infections among inner-city adolescent females. JAMA 1998;280:521-6.

8 Bravermann PK. Sexually trasmitted diseases in adolescents. Med Clin N Am 2000:84:869-89.

9 De Seta F, Sartore A, Piccoli M, et al. Gynecologic infections in adolescence. Minerva Ginecol 2000;52:327-32. 